\title{
刍议网媒对高校管理沟通课程改革的启示
}

檀璐

国网山西省电力公司技能培训中心山西电力职业技术学院

DOI:10.32629/er.v2i4.1777

[摘 要] 网络媒体正处于高速的发展阶段,在信息传播、传播内容等方面相对传统媒体都有很大程度上的改变,人们更多的通过 网络媒体获取自身需求的信息。高校管理沟通课程的主要教学目是让学生掌握沟通的方法和技能,培养学生书面和口头沟通表 达能力。网络媒体的高速发展对于高校管理沟通课程起到了一定程度的影响。本文在以网络媒体信息传播的特征分析作为切 入点,分析了网络媒体对高校管理沟通课程的多方面影响,最后提出通过网络媒体促进高校管理沟通课程改革的具体策略。

[关键词] 网络媒体; 高校; 管理沟通课程; 改革

\section{1 网络媒体信息交流的特征分析}

网络媒体在信息传播的过程中, 不受传统媒体的相关限 制, 可以将海量的信息即时展现给用户, 很大程度上促进了 人与人之间的交流。在教学过程中, 教师和学生可以随时随 地利用网络媒体进行相互通信, 便捷的与他人建立联系, 并 互相交换各自需要的信息, 在网络媒体中可以更加充分的表 达自己的切身感受, 发表自己的全部意见。同时网络媒体提 供了大量的共享资源, 极大程度上满足了人们对信息资源的 需要, 通过网络媒体进行信息交流, 可以让教师和学生在各 方面都得到了满足, 在很大程度上激发他们参与互动沟通的 主观意愿。

\section{2 网络媒体对高校管理沟通课程的影响}

在网络媒体主导的大环境下, 高校如何准确把握管理沟 通课程的变化特征, 是开展课程改革的首要条件。目前网络 媒体的发展必然会对高校管理沟通课程的教学起到一定程 度上的影响。网络媒体能够轻易的拉近人们在网络媒体上的 在线距离, 同时也在一定程度上降低了现实生活中人的沟通 和交往能力, 弱化人与人之间的沟通技能。首先高校管理沟 通课程要注重正确的吸收和利用网络媒体, 将网络媒体作为 课程教学的有力工具, 在教学中客观理性的利用网络媒体进 行沟通。

2.1 网络媒体使高校管理沟通课程教学模式趋于多样化 传统的教学模式中, 学生一般是在规定的时间内, 到制 定的教学场所进行学习, 教师对相应的课程进行讲解。网络 媒体可以轻易实现视频教学, 并在网络上完成相关的作业任 务, 信息传递的多样性, 可以对学生形成多方面的吸引, 提升 学生的学习兴趣。对于教师, 网络媒体可以大幅度减轻教师 的工作强度, 大量的共享资源可以在一定程度上取代了传统 的教案备课环节, 教学内容更加容易被学生接受, 教学过程 更加生动多彩。

2.2 网络媒体对于高校管理沟通课程环境有一定程度的 影响

首先体现在网络交流方面, 网络媒体中诞生了很多新形 势的沟通和交流方式, 使人们的沟通行为习惯在一定程度上
发生转变。网络媒体中, 会产生很多新奇、独特的语言交流 体系, 可以通过设计好的表情图标, 更简洁的符号语言, 字母 简称等来完成高质量的沟通, 这种语言体系具有很强的吸引 力, 同时易于接受, 逐步受到人们的偏爱。网络语言的组合形 式比较随意, 同时不受规定语法的限制, 学生通过网络媒体 进行沟通的过程中, 必须熟练掌握网络语言, 同时自身的语 言表达更加趋于口语化和通俗化。

2.3 网络媒体对高校管理沟通课程学习有一定的促进作用

网络媒体在一定程度上弱化了教师的施教作用, 促进了 教师和学生的沟通平等化, 通过网络媒体的多样化形式, 教 师可以将管理沟通课程的教学内容进行深度融合, 同时将课 程的主要价值观念、实践技能等更多的作为网络资源, 平等 的传递给学生, 学生更加容易接受, 减少抵触感。通过网络媒 体, 可以打破课堂顾虑, 有利于学生将自己最真实的情况表 达出来, 促进人与人之间心灵上的沟通, 通过类似的方式, 可 以进一步促进学生的心理健康。

2.4 网络媒体有助于教师之间建立高效交流平台, 准确 把握学生动态

网络媒体可以加强教师之间的相互沟通, 为教师与教师 之间建立良好的沟通平台, 取代以往的座谈、汇报等低效的 交流方式, 有助于教师把握问题的关键, 达到更好的交流和 学习效果。通过网络媒体教师可以更广泛的了解到学生思想 和行为动态, 网络媒体中的学生一般是真实的展示自身, 心 理等各方面需求都会在网络媒体中体现出来, 教师可以更容 易的掌握学生的世界观、人生观和价值观, 在后期的教学过 程中加以正确的引导。

\section{3 网络媒体对高校管理沟通课程的优化策略}

3.1 高校管理沟通课程内容需要根据网络媒体特征进行 优化

高校管理沟通课程体系各部分内容都具有相对的意义, 在优化的过程中必须做到结构主体明晰。结合网络媒体即时 性特征, 将当前学生关注的内容作为教学素材, 针对学生关 注的热点问题, 深入发掘其中有关课程教学的关联。在教学 过程中可加入相应的素材, 充分调动学生学习的积极性, 实 
现教学和实际相结合。高校管理沟通课程应更加贴近生活现 实, 冲破传统媒体的局限性, 利用网络媒体大信息量、自主选 择等特性, 开展课程与现实社会的共同研究工作, 促使学生 学到的沟通技能可以解决社会中存在的实际问题, 真正做到 学以致用, 不与社会脱节。优化后的高校管理沟通课程应突 出全面性, 通过网络媒体实现学生管理沟通课程学习与社会 全面发展的关联, 沟通技能更加注重整体性, 沟通方式更加 丰富。高校管理沟通课程应充分考虑网络媒体环境中学生的 实际利益, 学生通过网络媒体, 可以有多方面的渠道获取所 需信息, 更加容易甄别所学的内容是否符合自身适应社会的 需要, 脱离实际的课程会导致学生的反感和抵制。结合学生 实际的课程改革, 可以让学生变被动学习为主动, 提高学生 适应社会需求的能力, 切实拓宽学生视野。

3.2 院校有关部门应高度重视校园网络信息平台建设工作 高校管理沟通课程走进学生的日常生活, 与学生的行为 和语言进行全面的关联, 是高校进行管理沟通课程改革的一 项主要工程。网络媒体目前是学生获取信息的主要渠道, 通 过建立公共平台的方式可以发挥校园网络的最大化作用, 有 效的引导学生的学习方向。校园网络便于学生进行校园内信 息共享和在线学习, 进行校内的全方面交流。网络媒体的特 征和具体作用可以通过校园网络充分的体现, 校园网络平台 应建设成为功能全面, 具有趣味性、覆盖面广的全方位服务 平台。校园网应建立管理沟通课程的专项功能, 借助校园网 络开展学生的沟通交流活动, 切实拉近校园内所有人员的实 际沟通距离。在校园网络管理中应进一步加强管理力度, 正 确引导舆情走向。由于网络媒体存在开放性的特征, 校园网 络的管理过程相对复杂, 需建立一套科学的管理体系, 对校 园网络信息进行全方位的监管, 保证校园网络对管理沟通课 程的正确引导价值。

3.3 运用新媒体技术共享高校管理沟通课程学习资源

传统的学习过程主要是通过理论灌输的模式, 使学生对 理论学习有一定程度上的掌握和运用, 教师在整个教学过程 中一般占主体地位。通过网络媒体可以使理论灌输形式更加 多样化, 同时可以创新高校管理沟通课程教育模式。管理沟 通课程涉及面相对较广, 主要的核心内容是让学生利用沟通 解决现实中的问题, 过程比较抽象, 网络媒体资源可以将课 程内容进行分层设计, 将现实问题进行逐层分解, 对于已分 的层次进行注解标注, 有助于学生逻辑思维的发展, 充分利
用沟通的技能关联问题的各个层面, 最后达到全面解决问题 的效果。网络媒体同时可以将音频、视频、文字等内容进行 有机的融合, 形成新的课程资源, 将抽象的内容转换为具体 的展示内容, 有助于学生主动接受。

3.4 利用网络媒体实现管理沟通课程专有空间化的学习 方式

在网络媒体的大环境下, 学生在接受教育的同时, 也成 为了教学过程中的主体, 学生之间进行沟通时也会起到教师 的角色, 网络媒体上接收到信息会成为学生沟通的理论依据, 学生之间更容易接受网络媒体信息的暗示。通过网络媒体构 建管理沟通课程专有空间, 在空间中大量汇集优质的教学资 源, 充分建立专业教学人员和学生之间的互动, 通过群体的 作用, 使学生充分的体验和经历沟通过程。专有空间的建立 可以进一步减少高校管理沟通课程教学的差异性, 通过空间 共享, 可以打破院校与院校之间的教学差异, 提高各高校教 师的教学水平, 同时也可以提升各高校的管理沟通课程学科 建设水平。学生有更多的机会接触到校外的特色沟通课程教 育, 体会其他高校管理沟通课程的学习氛围, 达到拓宽学生 视野, 提升学生科学学习素养的目的。

\section{4 结束语}

网络媒体环境下, 高校管理沟通课程面临新机遇和挑 战。深入研究网络媒体影响下的高校管理沟通课程改革, 对 于提升课程教学质量, 正确引导学生提升沟通实践能力具有 重要的意义。由于网络媒体发展进步具有高速性的特征, 要 求相关的研究工作应结合网络媒体的发展, 进行长期不间断 的研究, 更好的使网络媒体为高校管理沟通课程改革和优化 工作服务。

\section{[参考文献]}

[1]范爱春.网媒对高校管理沟通课程改革的启示 [J].新 闻战线,2015,(04):121-122.

[2]杨彩玲.管理沟通教学中视频案例教学的探索与实践 [J].科技视界,2013,(32):75-76.

[3]康青,金志东,农佳武,等.网络多媒体视角下的管理沟 通课程新型学习模式初探[ ] ] 华东理工大学学报(社会科学 版),2012,27(05):102-108.

[4]周丽琴,孙玮。职业院校新媒体人才培养模式改革研 究[J].现代经济信息,2019,(03):466. 